\title{
Transgressividade em The Catcher in the Rye de J.D. Salinger e sua recepção nas traduções para outros idiomas: português, espanhol, francês, italiano e holandês ${ }^{1}$
}

John Robert Schmitr.

\begin{abstract}
Resumo: Divido esta reflexão em quatro partes. Inicio com uma apresentação do texto original e as obras traduحidas para o português, o espanhol, o francês, o italiano e o holandês. Na segunda parte, refiro-me ao impacto que o romance The Catcher in the Rye de autoria de J.D. Salinger teve logo após a sua publicação nos Estados Unidos nos anos 40 do século passado. Na terceira seção, analiso duas cenas transgressivas no original e casos de supressão nas diferentes traduçöes. Na quarta parte, examino a dificuldade que alguns dos tradutores tiveram com as palavras "fuck you" encontradas nas paredes dos edifícios aonde o protagonista se dirige. Na última parte, apresento conclusões sobre o perigo da censura no ato tradutório, a coragem do tradutor que busca a sua própria autoria, lealdade ao autor da obra original ou à comunidade interpretativa a que pertence o tradutor e a invisibilidade que ainda está presente na concepção dos tradutores e do trabalho desses profissionais por parte do público em geral.
\end{abstract}

Palavras-chave: supressão de linguagem, independência do tradutor, transgressividade.

\section{Apresentação}

O romancista norte-americano Jerome David SALINGER, falecido aos 91 anos no início de 2010, teve a sua obra-mestra The Catcher in the Rye (London: Penguin Books, [1951], 1994) traduzida para um número grande de idiomas entre

1 Quero agradecer a professora Dra. Claudia Zavaglia (UNESP-Rio Preto) pela leitura crítica deste trabalho e suas valiosas sugestões. Meus agradecimentos a Willy Portugaels pela indicação da tradução em língua holandesa e a Marluce Portugaels pelos comentários. Sou plenamente responsável pelas falhas que podem permanecer. 
eles o francês, o espanhol, o italiano, o holandês, o russo e o japonês. A língua portuguesa não é uma exceção, pois além da versão brasileira que tem por título O Apanhador no Campo de Centeio (traduzida por Álvaro ALENCAR, Antônio ROCHA e Jório DAUSTER, Rio de Janeiro: Editora do Autor, $4^{a}$ ed. 1967), existem duas traduções lusas, a primeira intitulada Uma Agulha no Palheiro (traduzida por João PALMA-FERREIRA, Lisboa: Edição Livros do Brasil, 1967 [1984]) e a segunda À Espera no Centeio (elaborada por José LIMA, Algés: Portugal DIFEL, 2005).

O objeto desta reflexão é comparar a versão original em língua inglesa com as três traduções em português (citadas acima) e também com traduções em outros idiomas, nomeadamente: espanhol, francês, holandês e italiano:

. El Guardián entre el Centeno. Madrid: Alianza Editorial, S.A. 1978 [2005]. [Carmen CRIADO].

. L'Attrape-ccurs. Paris: Robert Laffont, 1986. [Annie SAUMONT].

De Vanger in Het Graan. Amsterdam: De Bezige Bij, 2008. [Johan HOS].

. Il Giovane Holden. Torino: Giulio Einaudi Editora, 2008. [Adriana MOTTI].

\section{O romance e seu impacto na sociedade americana nos anos 50 e 60}

O Apanhador no Campo de Centeio de autoria de J. D. Salinger foi um sucesso imediato nos EUA logo após a sua publicação no início da década de 50. Todavia, o romance chegou a irritar certos setores tradicionais e conservadores devido ao uso, por parte do adolescente Holden Caulfield, por um lado, de linguagem informal e vulgar e, por outro, pelas suas críticas ao materialismo e à hipocrisia reinantes na sociedade estadunidense naquela época. Daí se vê que houve censura e até a retirada do livro de certas bibliotecas e a proibição da leitura de livros em certos colégios públicos e particulares.

De fato, o jovem rebelde, ao longo da sua autobiografia, fez uma série de comentários que escandalizou certos grupos de leitores no país. Dizer que o exército norte-americano “.... estava praticamente tão cheio de filhos da puta quanto os nazistas" (Tradução, Alencar et. al, Cap. 18:124), asseverar que “... quanto mais caro um colégio, mais gente safada tem, no duro" (Cap. 1:11) ou declarar que "não é preciso pensar muito quando se fala com um professor" (Cap. 2:19) desagradaram a alguns setores estadunidenses.

Daí se vê que o romance, para a época em que foi produzido, mais especificamente o tempo após a Segunda Guerra Mundial, isto é, a segunda metade da 
década de 40 e a de 50 do século passado, foi bastante transgressivo tanto com respeito aos temas abordados como também em relação à linguagem informal utilizada. Salinger tentou publicar, sem sucesso, partes de Catcher em forma de contos em revistas literárias norte-americanas antes da guerra; todavia, devido à resistência a referências a sexo em cenas explícitas, ao uso de linguagem chula e a crítica à hipocrisia e ao materialismo reinante na sociedade americana, os contos não foram aceitos. Traduzir para outros idiomas uma obra repleta de palavrões e de linguagem não padrão, repleta de expressões idiomáticas e gírias utilizadas pela juventude americana da época resultou um desafio para os que cogitaram em recriar o romance em outro idioma e respectiva cultura.

\section{Cenas transgressivas do original e supressão nas traduções}

Momento de irreverência: incidente na capela durante a fala de um exaluno bem sucedido na vida

O Sr. Ossenberger, ex-aluno da escola onde Holden Caulfied estudava, ganhou muito dinheiro graças à construção de uma rede nacional de funerárias e depois doou uma dinheirama à escola, que deu o nome "Pavilhão Ossenberger" (Tradução: Alencar et. al, Cap. 3:21) (Ossenberger Memorial Wing) em homenagem ao distinto benfeitor. Num determinado dia, o mecenas foi convidado a dar uma palestra na capela da instituição e durante a sua fala, ocorreu um incidente irreverente, mas engraçado:

He [Ossenberger] was telling us all about what a swell guy he was, what a hot-shot and all, then all of a sudden this guy sitting in the row in front of me, Edgar Marsalla, laid this terrific fart. (SALINGER, The Catcher in the Rye, C. 3:14-15)

João Palma-Ferreira elimina a irreverência e também o humor do incidente trocando o vocábulo peido por arroto, uma função corporal normalmente involuntária:

Contava-nos ele que era um tipo todo fixe quando, de súbito, o rapaz que estava sentado mesmo na minha frente, Edgar Marsalla, deu um tremendo arroto. (SALINGER, Uma Agulha no Palheiro, 1976 [1984], C. 3:26 [João Palma-Ferreira]).

Palma-Ferreira é o único entre os tradutores aqui analisados que modificou a cena, devido, possivelmente, ao fato de que a obra de Salinger foi traduzida 
em Portugal durante a época do regime militar do general Antonio de Oliveira Salazar (1932-1968). Ditaduras tentam controlar o pensamento e o comportamento alheio. Pode ser que a referência escatológica tenha incomodado o próprio tradutor e ele não quis correr o risco de ofender seus leitores.

Os outros tradutores traduziram a cena sem supressões. Exemplificando, o tradutor lusitano mais recente foi direto: "mandou um peido do caraças" (José Lima, C. 3:26); os três tradutores brasileiros (Álvaro Alencar, Antônio Rocha, Jório Dauster, C. 3:22) "soltou um peido infernal"; a tradutora espanhola (Carmen Criado, C. 3:24) "se tiró um pedo tremendo"; a tradutora italiana (Adriana Motti, C. 3:21) "mollò una scorreggia tremenda"; a tradutora francesa (Annie Saumont, C. 3:28) "il a lâché um pet suberbe" e o tradutor para o holandês (Johan Hos, C. 3:28) "opeens een ontzettende scheet".

Outra fala irreverente é o comentário a respeito da mãe da namorada de Holden. Ele diz:

And old Sally Hayes's mother. Jesus Christ. The only way she could go around with a basket collecting dough would be if everybody kissed her ass for her when they made a contribution (SALINGER, The Catcher in the Rye, Cap 16: 103).

Dentre as sete traduções examinadas, cinco delas evitam traduzir "kissed her ass for her". Na de língua espanhola, a parte do corpo humano é outra: "se comprometiera a besarle primero los pies" (Criado, Cap. 16:126). A tradutora de língua francesa foge completamente da imagem da versão original: "que les gens en lui donnant leur obole seront babas d'admiration." (Saumont. Cap. 16, 140). Semelhantemente, os tradutores brasileiros atenuam em muito a imagem transgressiva da original inglesa:

E a mãe de Sally Hayes! Puxa vida. Só via um jeito dela sair recolhendo dinheiro numa cesta: era se todo mundo ainda tivesse que fazer a maior reverência, se dobrar até o chão, cada vez que entregasse um donativo (SALINGER, O Apanhador no Campo de Centeio [Álvaro Alencar, Antonio Rocha e Jório Dauster, Cap. 16:103].

As traduções em italiano e em português (a mais recente, Lima, 2005) são parecidas, pois recorrem respectivamente à indumentária: "solo a patto che nel dare l'offerta tutti quanti le leccassero gli stivali." (Motti, Cap. 16:134); "a pedir esmola com um cestinho na mão era se todos lhe lambessem as botas quando davam alguma coisa" (Lima, Cap. 16:127). 
As duas traduções que mantêm a imagem da original são a holandesa e a portuguesa (1967) que, neste caso, não a suprimem:

En de moeder van Sally Hayes. Jezus christus. Die zou alleen met een mandje gaan collecteren als iedereen die iets bijdroeg zo'n beetje haar reet zou likken. (SALINGER, De Vanger in Het Graan, José Lima, Cap. 16: 157]).

E a mãe de Sally Hayes! Meu Deus! Só consentiria em fazer um peditório com um cesto de Natal se em paga lhe beijassem o rabo! (SALINGER, Uma Agulha no Palheiro, [João Palma-Ferreira, Cap. 16:133]).

Há duas hipóteses para o uso de "beijassem o rabo!" na tradução de Palma-Ferreira. Pode ser que o trecho tenha escapado ao olhar da censura do governo militar no poder em Portugal, ou a expressão "beijar o rabo" no país seja corrente. DAUSTER (2010) critica, talvez injustamente, o tradutor português por traduzir "foda-se" como "vai à merda" e "peido" por "arroto", mas é bom lembrar que todos os tradutores podem ter três censores: (i) o próprio Autor, (ii) a editora e (iii) o público ledor.

\section{A expressão fuck you e sua recepção nas outras traduções}

Mesmo em língua inglesa a versão original estadunidense foi censurada quando publicada na Inglaterra no que diz respeito à ortografia, por um lado, e à linguagem chula, por outro, na edição britânica. A grafia britânica foi imposta e assim o inglês americano curb (meio-fio) foi alterado para kerb (SCHMITZ, 1998). A expressão considerada "vulgar" como fuck you foi reduzida para "f__." Comparem a versão americana com a inglesa:

But while I was sitting down, I saw something that drove me crazy. Somebody'd written "Fuck you" on the wall. (Cap. 25:180-181. Boston, Mass.: Little, Brown and Company, 1951).

But while I was sitting down, I saw something that drove me crazy. Somebody'd written "-_- you” on the wall. (Cap. 15:180-181. Harmondsworth, United Kingdom: Hamish Hamilton, 1951.

As edições subsequentes no Reino Unido continuaram a política de supressão (iniciada em 1951) até 1994, quando a Penguin Books Londres informou nestes termos, "escondidos" na capa de trás, em letras bem pequenas: "This new edition reproduces, for the first time in Penguin Books, the original American text". 
Daí se vê que não é de se surpreender que a obra, nas diferentes traduções em outros idiomas e outras culturas, tenha sofrido modificações com respeito à recepção de determinadas cenas, especificamente aquelas que apresentam linguagem chula ou referências a sexo e funções do corpo humano.

Os tradutores brasileiros traduzem com todas as letras a expressão "fuck you" ao passo que o tradutor português a suprime como se vê ao comparar respectivamente a brasileira com a portuguesa:

Aí de repente, vi aquilo na parede. Outro "Foda-se". Escrito com lápis vermelho ou coisa parecida, bem embaixo da parte envidraçada da parede, perto das pedras. (SALINGER, O Apanhador no Campo de Centeio (1967) $4^{a}$ edição. Cap. 25:176. [Álvaro Alencar, Antônio Rocha e Jório Dauster])

O tradutor lusitano suprime a referida expressão e coloca outra que nada tem a ver com as duas palavras escritas na parede:

Mas quando estava sentado vi uma coisa que me deixou varado. Alguém escrevera na parede: "Vai à merda". (SALINGER, Uma Agulha no Palheiro (1967), Cap. 25:223. [João Palma-Ferreira].)

No decorrer do romance a expressão "fuck you" ocorre mais uma vez, justamente na escola onde a irmã de Holden Caulfied estuda. Ao visitar a escola, o protagonista se depara novamente com a expressão:

Desci por outra escada e vi outro "Foda-se" na parede. Tentei apagar outra vez com a mão, mas esse tinha sido riscado na parede, com um canivete ou coisa parecida. (SALINGER, O Apanhador no Campo de Centeio, C. 25:175. [Álvaro Alencar, Antônio Rocha e Jório Dauster]).

Palma-Ferreira evita traduzir a expressão a todo custo; ele apresenta uma tradução equivocada, pois somente há uma expressão riscada no texto original e não várias:

Desci por outra escada e voltei a encontrar novos palavrões pelas paredes. Tentei apagá-los, mas estavam gravados a canivete. (SALINGER, Uma Agulha no Palheiro, 1967 Cap. 25:224 [ João Palma-Ferreira])

Na segunda tradução lusitana publicada bem mais recente (2005), num Portugal democrático, observamos que a obra está livre de censura: 
Desci por outras escadas e vi outro "Vai te foder" na parede. Tentei também apagá-lo com a mão, mas este estava gravado com um canivete ou coisa assim. (SALINGER, À Espera no Centeio, 2005. Cap. 25:215. एJosé Lima].)

Com respeito às outras obras, a tradução holandesa, em comparação com a espanhola, a francesa e a italiana, é a única que reproduz o verbo "fuck". A tradução holandesa se aproxima à obra original:

Ik nam een andere trap naar beneden en ik zag nog een "Fuck" op de muur staan. (SALINGER, De Vanger in Het Graan, Cap. 25:273). JJohan Hos 2008].)

Quase como no caso da versão inglesa que omite a palavra fuck oferecendo somente o pronome you (“___you”), a tradutora em língua espanhola apresenta a primeira letra do verbo em espanhol, isto é, a letra $J$, assim omitindo quatro letras do vocábulo joder. É procedente recorrer ao verbo joder porque este é relacionado o verbo foder, mas o que não procede é a mutilação da palavra espanhola. Quem está sendo "protegido" com esse tipo de censura?

Bajé por una escalera diferente y vi outro J... en la pared. Quise borrarlo con la mano también, pero en este caso ló habían grabado con una navaja o algo así. (SALINGER, El guardián entre el centeno. Cap. 25:214) [Carmen Criado].

É possível que a tradutora do romance em língua espanhola tenha sido influenciada pela versão inglesa, que suprimiu a palavra "fuck" deixando somente o pronome: " you". A estratégia de tradução utilizada pela tradutora em língua italiana não é feliz porque substitui com outro vocábulo, isto é, "ca" (de cazzo) que não é equivalente à expressão "fuck you" do inglês:

Scesi per un'altra scala, e vide un altro "ca..." sul muro. Cercai di cancellare con la mano anche questo, ma questo l'avevano graffiato con un temperino o vattelappesca. Il Giovane Holden. [1961], 2008, C. 25:235. [Andrea Motti].

O problema com a escolha de "ca..." ou cazzo em italiano é que existe no idioma as expressões "va a farti fottere" e "fottiti". A palavra "cazzo" tem em português e em outros idiomas várias possibilidades tradutórias como, por exemplo, caralho, cacete e outras, dependendo do contexto. $O$ fato de a tradutora não optar por "fottiti" ou "va a farti fottere" pode ser atribuído a uma imposição da 
editora, com o intuito de se proteger das críticas dos puristas e moralistas de plantão.

A tradução em língua francesa também censura o original porque, como em italiano, existe a expressão em francês "va te faire foutre". A tradutora da versão francesa - como no caso da versão inglesa que omite as quatro letras completas da palavra e também como no caso da tradutora de língua espanhola que apresenta uma equivalente incompleta "J..." - opta pelo verbo enculer, mas com a supressão de cinco letras:

Je suis descendu par un autre escalier, et j'ai vu un autre "Je t'enc..." sur le mur. Celui-là aussi j'ai essayé de l'effacer avec ma main mais il était gravé au couteau ou avec autre chose. (SALINGER, L'Attrape-cours C. 25:240. [Traduit de l'américain, par Annie Saumont].)

\section{As ocorrências do fuck you escrito nas paredes e o problema pessoal do jovem Holden Caulfield com respeito à sexualidade e à vida adulta}

Além dos seus problemas acadêmicos (ele foi reprovado em mais uma escola e devidamente expulso), Holden ainda não aceita a realidade da morte de seu irmão mais novo. Ele se sente "perdido" na vida. A mãe e o pai vivem juntos, mas o pai, embora mencionado, nunca aparece no romance; a mãe dele nunca fala diretamente com ele. Diante desse quadro complicado, o jovem abandona a escola repentinamente e se dirige à cidade de Nova York à procura de companhia, amizade e aventura antes de voltar a sua casa e confrontar os pais.

No final do romance, precisamente no capítulo 25, Holden se depara com três instâncias da expressão "fuck you"; as duas primeiras, como vimos, escritas nas paredes da escola onde a sua irmã estuda. A primeira ele consegue apagar, mas a segunda, riscada com um instrumento cortante, é indelével. Holden acha a expressão pela terceira vez escrita com giz de cera ao lado de uma exposição de múmias egípcias num museu da cidade.

No decorrer do romance, Holden de fato emprega muitos palavrões e gírias típicas dos jovens americanos da época, mas nunca usa a expressão "fuck you" nas suas interações com os outros. O que acontece que a referida expressão o deixa "maluco de raiva" e "furioso de ódio" (Alencar et. al, Cap. 25:174)? Se os tradutores que deixaram de procurar um equivalente para "fuck you" tivessem lido com mais atenção as palavras do jovem narrador que revelam problemas relacionados à sexualidade, acredito que teriam refletido melhor. Holden explica claramente a sua dificuldade: 
Imaginei a Phoebe (a sua irmã) e todas as outras crianças lendo o que estava escrito: iam ficar pensando que diabo significava aquilo, até que, afinal, algum garoto sujo ia dizer a elas - naturalmente tudo errado - o que queria dizer aquela palavra. (SALINGER, O Apanhador no Campo de Centeio, Cap. 25:174 [Álvaro Alencar, Antônio Rocha e Jório Dauster]).

A escolha de "vai à merda" por parte de Palma-Ferreira não tem nada a ver com sexualidade; a irmã de Holden ou as colegas de classe não dariam importância à referida expressão. A escolha por parte da tradutora de língua italiana do vocábulo "ca" não motivaria perguntas sobre o ato sexual; a decisão de escrever “je t' enc...” por parte da tradução francesa poderia levantar perguntas por parte de "outras crianças", mas considerando que existem em francês palavras equivalentes (como disse acima) a supressão das letras do verbo não reflete o que ocorre no mundo real. A falta de atenção dos tradutores (Palma-Ferreira e Motti) no que diz respeito à violenta reação de Holden ao ver "fuck you" escrito nas paredes contribui para tornar as respectivas traduções inverossímeis (pelo menos neste item), pois um protagonista que emprega correntemente palavras como "bastard", "turd", "goddam", "sonuvabitch", "christake" ou a expressão "not to know one's ass from one's elbow", "you give me a royal pain in the ass" (COSTELLO, 1959) não teria nenhum ataque com os vocábulos usados: "va à merda" ou "ca" respectivamente nas traduções. A estratégia tradutória de escrever somente parte da expressão como “_ you”, “J.” ou “je t’enc...” não reflete o que ocorre no mundo real onde as palavras aparecem na íntegra em muros e cartazes.

\section{The Catcher in the Rye e seu título em outros idiomas}

O título em língua inglesa deve sua origem ao poema “Comin thro' the Rye”, de autoria de Robert Burns. Quando Phoebe, a irmã de Holden, cobra dele o que ele quer ser na vida, o jovem responde:

That's all I'd do all day. I'd just be the catcher in the rye and all. I know it's crazy, but that's the only thing I'd really like to be. I know it's crazy. (SALINGER, The Catcher in the Rye. Cap. 22:156).

Os tradutores brasileiros (Alencar, Rocha e Dauster) tentaram mudar o título do romance e propuseram "A Sentinela do Abismo", mas Salinger não permitiu, pelo menos no caso desses tradutores, que o título da obra fosse traduzido de outra forma. Foram obrigados a manter a tradução literal da original: $\mathrm{O}$ 
Apanhador/ Catcher; no Campo de Centeio/ in the Rye [Field]. Mas os tradutores mantiveram no interior do romance as palavras exatas que desejavam utilizar como título do romance. Comparem o original acima com a tradução:

Só isso que eu ia fazer o dia todo. Ia ser só a sentinela do abismo e tudo. Sei que é maluquice, mas é a única coisa que eu queria fazer. Sei que é maluquice. (SALINGER, The Catcher in the Rye. $4^{a}$ ed., Cap. 22:151 [Álvaro Alencar, Antônio Rocha e Jório Dauster]).

Sublinhei acima as palavras a sentinela do abismo e tudo que constavam da $4^{\mathrm{a}}$ edição. Ao compará-la com a $17^{\mathrm{a}}$ edição (sem data), o leitor vai observar que o trecho "a sentinela..." foi alterado para o apanhador no campo de centeio e tudo:

Só isso que eu ia fazer o dia todo. Ia ser só o apanhador no campo de centeio e tudo. Sei que é maluquice, mas é a única coisa que eu queria fazer. Sei que é maluquice. (SALINGER, The Catcher in the Rye. $17^{\mathrm{a}}$ edição, Cap. 22:156 [Álvaro Alencar, Antonio Rocha e Jório Dauster]).

Tenho em mãos a quarta edição do romance e não sei a partir de qual edição a editora mudou o texto de acordo com a exigência de Salinger e de seu agente. Ausente também da $17^{a}$ edição são as palavras que constam do meu exemplar da $4^{a}$ edição: "Os três jovens diplomatas brasileiros que fizeram a presente tradução escolheram o título 'A Sentinela do Abismo'. O Autor preferiu, entretanto, intitulá-lo 'O Apanhador no Campo de Centeio'." Salinger foi um autor que ao longo de sua vida tentou proteger a sua obra de alterações por parte dos diferentes tradutores. Ele recorreu a um agente e advogados para fiscalizar a fidelidade. Muito diferente é a postura de Guimarães Rosa que também tentava controlar, mas conhecia vários idiomas e se correspondia com os seus tradutores e interagia com eles (ARMSTRONG, 2001).

É louvável a postura corajosa dos três tradutores de não adotar uma posição subserviente com respeito ao sempre todo-poderoso Autor. Com respeito à censura e transgressão, Schmitz (1998) apresenta uma reflexão mais detalhada sobre a "rebeldia" por parte dos referidos tradutores.

É curioso que Palma-Ferreira conseguiu fazer imprimir o título Uma Agutha no Palheiro quando os brasileiros foram impedidos de alterá-lo. O tradutor lusitano informa na "Advertência" a sua tradução que ele tem esperança de que o título Uma Agulha... não fuja “ ao que o escritor pretendeu” e acredita que o referido título "marcará incisivamente o espírito deste livro admirável". O que seria na realidade o "espírito" da obra? Como podemos averiguar o que o autor 
realmente "pretendeu"? Na verdade, a expressão "agulha/palheiro" é muito comum em português, mas também em outros idiomas, por exemplo, o inglês "A needle in the haystack". Possivelmente, Palma-Ferreira chegou ao título Uma Agulha no Palheiro devido ao fato de Holden ter sido um "quester", isto é uma pessoa que "busca" um ideal, um mundo "perfeito" ou algo inatingível ou inexistente.

O problema, no caso, é que o tradutor não traz o título por ele utilizado à cena em que Holden informa o que ele deseja fazer na vida (como Alencar, Rocha e Dauster fizeram). Eis a tradução de Palma-Ferreira:

Gostava de fazer isso o dia inteiro. Seria apenas o vigia do campo de centeio. Sei que é uma parvoíce, mas seria a única coisa que me agradaria. Mas, sei que é uma parvoíce. (SALINGER, Uma Agulha no Palheiro, Cap. 22:196. [João Palma-Ferreira]).

Palma-Ferreira mantém "campo de centeio" na fala de Holden, mas ao invés de "apanhador", ele opta por "vigia". Da mesma forma, a tradutora espanhola (Criado) traduz: "[Y]o sería el guardián entre el centeno" (Cap. 22:185) que reflete o título atribuído à obra (El guardián entre el centeno).

Não muito diferente é a tradução do segundo tradutor lusitano (Lima) que escreve: "Só estar ali à espera, a apanhar os miúdos no centeio e tal." (Cap. 22:187). [Grifo do tradutor].

A tradutora italiana (Motti) escreve: "Sarei soltanto l'acchiappatore nella segale e via dicendo" (Cap. 22:202) onde "acchiappatore" significa apanhador e "segale" campo de centeio. Todavia, a tradução italiana contém uma nota al titolo assinada pelo editor (e não pela tradutora) que comenta:

Il titolo di questo romanzo, The Catcher in the Rye, è intraducibile. Al suo significato se fa riferimento di sfuggita in due punti del libro (capp. xvi e xvii). La famosa canzone scozzese di Robert Burns cui si allude a una stofa que dice:

Gin a body meet a body

Coming through the rye;

Gin a body kiss a body,

Need a body cry?

O editor declara que, como título, "L’acchiappatore nella segale" não seria procedente para os leitores de língua italiana e por esse motivo conclui que "[C]i siamo quindi limitati a chiamare il romanzo col nome del protagonista". Daí se vê o título em italiano: Il Giovane Holden. 
O tradutor para o holandês (Hos, 2008) não é diferente dos tradutores das outras línguas: "Dan was ik dus de vanger in het graan" (p. 236) onde vanger significa " apanhador" e graan, "campo de centeio".

Annie Saumont, a tradutora da obra em língua francesa, apresenta um título muito diferente dos outros acima examinados: L'Attrape-ccurs. Dauster (2010) critica o título nestes termos: "dá para questionar a qualidade da versão gaulesa independentemente de sua dose excessiva de açúcar". Diria que o título em francês de nenhuma forma impediu a venda do livro na França e um grande número de leitores na França e em outros países francófonos conhecem a obra graças à tradução de Saumont. Um ponto positivo da tradução em língua francesa é a sua consistência interna, pois o próprio protagonista repete o título em resposta à pergunta de sua irmã:

Trouve encore une chose. Ben, ce que tu voudrais être plus tard. Par exemple, ingénieur. Ou conseiller juridique. (SALINGER, L'Attrape-cours. Cap. 22:207 [Annie Saumont]).

E a resposta de Holden:

Je serais juste l'attrape-caurs et tout. D'accord, c'est dingue, mais c'est vraiment ce que je voudrais être. Seulement ça. D'accord, c'est dingue. (SALINGER, L'Attrape-cours. Cap. 22:208 [Annie Saumont]).

Considero, por um lado, bastante criativo o título utilizado pela tradutora francesa, pois ele reflete o que o protagonista mais quer na vida: salvar não somente o corpo, mas a alma ou coração das pessoas das quedas na vida, isto é, dos indivíduos que "go over cliffs", "cair no abismo", "correr para o abismo", "cair en el precipicio", "cadere dal dirupo", "trop près du bord" e "afgrond dreigen te vallen". (PINSKER, 1993). Por outro, penso que a tradução em francês seja inovadora, pois a tradutora com o intuito de propor um título por ela julgado como significativo para os leitores franceses "cria" outro um mal-entendido por parte de Holden. Exemplificando, quando Holden pergunta para a irmã se ela conhece o referido poema de Burns: "Tu connais la chanson 'Se um cours attrape um cours que vient á travers les seigles"'? A irmã responde e corrige duas palavras (que sublinhei): "C'est 'Si um corps rencontre un corps que vient à travers les seigles'." Mesmo aceitando a correção, Holden informa que a sua missão na vida seria “juste l'attrape-cours et tout” (p. 208). Daí se vê que há uma ligação entre o título da tradução francesa e a afirmação por parte do protagonista do que ele quer fazer na vida. 


\section{À guisa de conclusão}

a. Insistir que o tradutor seja fiel ao título proposto pelo Autor caracteriza uma postura essencialista. $\mathrm{O}$ tradutor precisa ser leal à sua comunidade interpretativa. b. Toda censura com respeito ao ato tradutório é infeliz e tolda a independência do tradutor.

c. A falta de informação sobre a identidade do tradutor é um desserviço ao público que paga pela tradução. A prática de apresentar o nome do tradutor em letras pequenas na página atrás da contracapa mostra que tradutores renomados que traduziram a obra de Salinger continuam invisíveis. (VENUTI, 1995).

d. Louva-se, em primeiro lugar, a postura transgressiva dos tradutores brasileiros (Alencar, Rocha e Dauster) pela coragem de propor um título diferente e pela tentativa de inseri-lo na fala do protagonista e, em segundo lugar, a tradução criativa e inovadora em língua francesa (Saumont).

\section{Referências}

ARMSTRONG, Piers. Guimarães Rosa in Translation: scrittore, editore, traduttore, traditore. Luso-Brazilian Review. 38/1: 63-87. 2001.

COSTELLO, Donald P. The Language of the "The Catcher in the Rye" American Speech, vol. 51, n. 3, 1959

DAUSTER, Jório. De que vale um título? Cultura. 18 de janeiro de 2010.

PINSKER, Sanford. Chapter 6 "And Holden Caulfield Had a Great Fall”. The Catcher in the Rye: Innocence Under Pressure. New York: Twayne Publishers, 1993.

SCHMITZ, John. Robert. Suppression of References to Sex and Body Functions in the Brazilian and Portuguese Translations of The Catcher in the Rye. Meta (Journal des Traducteurs), vol. 43, n. 2 (junho), 1998.

VENUTI, Lawrence. The Translator's Invisibility. New York: Routledge, 1995. 